\title{
Association of Clinical Pathologists' surveys of infection in British clinical laboratories, 1970-1989
}

\author{
N R Grist, J A N Emslie
}

\section{Introduction}

Public and professional concern about the threat of hepatitis B to health workers, and laboratory staff in particular, followed several serious incidents and led to discussions in 1970 by the Committee on Microbiology of the Association of Clinical Pathologists (ACP). It emerged that adequate data were not available to permit proper assessment of the scale and severity of the threat. A series of surveys was therefore launched, initially (and continuing) through members of the ACP. The defined population of the laboratory staff provided denominator as well as numerator data so that rates of infection for various groups of laboratory workers could be calculated and used for comparisons and assessment of trends. The following text serves to summarise the observations recorded over two decades.

These surveys were initiated for, and primarily directed to, the problem of hepatitis which caused concern during the 1960 s. $^{12}$ For the second decade they were widened to cover infections of all types reported from collaborating laboratories. ${ }^{34}$ Data were collected by questionnaires distributed to members of the ACP. Supplementary contributions were obtained from 1980 from the heads of additional laboratories identified with the assistance of the Institute of Medical Laboratory Sciences (IMLS), and from 1986 from additional members of the British Association in Forensic Medicine. As explained in previous reviews, ${ }^{24}$ "laboratories" proved difficult to define because no list of British clinical laboratories could be identi-

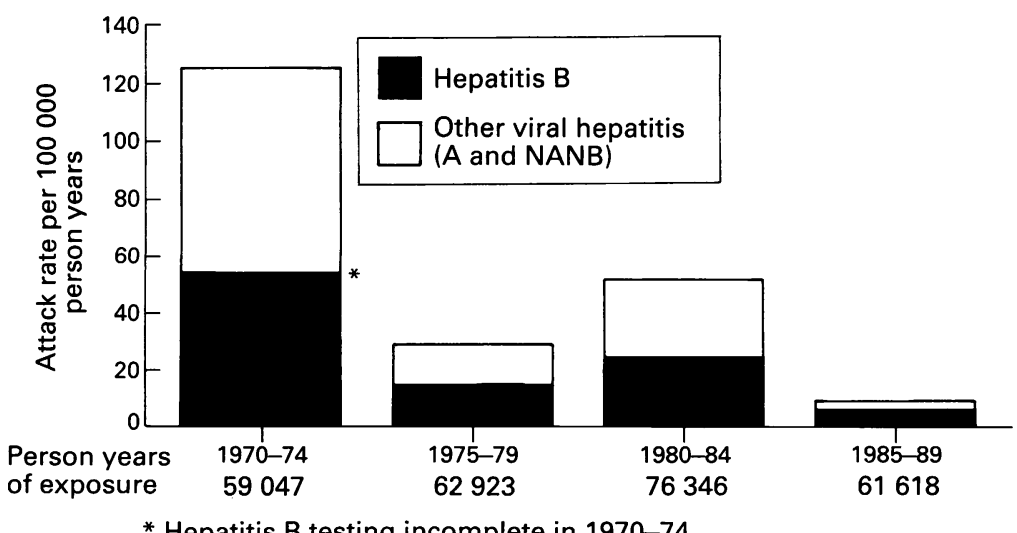

fied. The response rate of laboratories could not therefore be determined. Reports came from some single discipline units, most from multidisciplinary laboratories, and some from Laboratory Divisions. The numbers of "laboratories" reporting ranged from 208 to 337 in the first decade (mean 242) and from 166 to 260 in the second (mean 219), but with no trend towards fewer but larger laboratories reporting. ${ }^{5}$ After the early surveys the attempt to analyse data by type or nature of work of "laboratories" was abandoned and attack rates calculated only for different occupational disciplines of staff. To enlist good cooperation from participants, the questionnaires were progressively simplified, but further details were elicited by follow up forms for each reported case of infection. Complete confidentiality was maintained and any bias in these familiar, regular enquiries would probably be in the direction of exaggerated rates. $^{2}$ The results have been reported regularly, usually covering two year surveys, in this journal, from $1975^{6}$ to $1991 .^{5}$ Completion of the second decade permits consolidation of larger numbers and more stable calculation of rates for comparisons and assessments of trends.

\section{Hepatitis}

The findings for the first 10 years showed a sharp decline in incidence half way through the decade. ${ }^{27}$ This continued except for an increase in the five years 1980-84 (figure) which paralleled national trends for hepatitis B. ${ }^{8}$ Table 1 shows that morbid anatomy and haematology staff were still mainly involved, with cases also reported in post mortem and mortuary staff, and biochemistry and microbiology workers. Specific tests for hepatitis A were not available or little used for most of the first decade of the surveys. Most confirmed or probable hepatitis A cases followed exposure in the home or while abroad. Of the 22 hepatitis B cases in the second decade, five followed laboratory exposure or accidental self-inoculation, two were associated with clinical exposure to patients, and three were attributed to familial or social contact or to exposure in India. No causal factors were reported for the other 12 cases. Hepatitis B infections showed a male predominance of 5:1 and slightly older age distribution. The 11-fold fall in incidence over two decades 
Table 1 Hepatitis B, "V"^ reports 1980-84, 1985-89, (1970-79)

\begin{tabular}{|c|c|c|c|c|c|c|c|c|c|c|c|c|}
\hline \multirow[b]{3}{*}{ Group } & \multirow{2}{*}{\multicolumn{3}{|c|}{$\begin{array}{l}1980-84 \\
\text { No of cases }\end{array}$}} & \multirow{2}{*}{\multicolumn{3}{|c|}{$\begin{array}{l}1985-89 \\
\text { No of cases }\end{array}$}} & \multicolumn{6}{|c|}{ Rate/100,000 P-Y } \\
\hline & & & & & & & \multicolumn{2}{|c|}{$1980-84$} & \multicolumn{2}{|c|}{$1985-89$} & \multicolumn{2}{|c|}{$(1970-79)$} \\
\hline & $B$ & $V$ & $P-Y \dagger$ & $B$ & $V$ & $P-Y \dagger$ & $B$ & $V$ & $B$ & $V$ & $B$ & $V$ \\
\hline \multicolumn{13}{|l|}{ Morbid anatomy } \\
\hline Medical & 2 & 0 & 2746 & 0 & 1 & 2359 & 73 & 0 & 0 & 42 & $(48$ & 48) \\
\hline Scientific (PTA) & 0 & 0 & 419 & 0 & 0 & 313 & 0 & 0 & 0 & 0 & $(277$ & $0)$ \\
\hline MLSO (PTB) & 0 & 0 & 6977 & 0 & 0 & 5677 & 0 & 0 & 0 & 0 & 9 & 19) \\
\hline Post mortem technician & 1 & 2 & 825 & 0 & 0 & 1236 & 121 & 243 & 0 & 0 & 0 & 0) \\
\hline Mortuary attendant & 1 & 0 & 156 & 0 & 0 & 126 & 641 & 0 & 0 & 0 & & 0) \\
\hline \multicolumn{13}{|l|}{ Biochemistry } \\
\hline Medical & 1 & 0 & 758 & 0 & 0 & 602 & 132 & 0 & 0 & 0 & 0 & 0) \\
\hline Scientific (PTA) & 0 & 1 & 2251 & 1 & 0 & 1757 & 0 & 44 & 57 & 0 & 78 & 52) \\
\hline MLSO (PTB) & 2 & 3 & 10275 & 0 & 0 & 8036 & 19 & 29 & 0 & 0 & $(69$ & 69) \\
\hline \multicolumn{13}{|l|}{ Haematology } \\
\hline Medical & 1 & 1 & 1929 & 0 & 0 & 1502 & 52 & 52 & 0 & 0 & $(52$ & 103) \\
\hline Scientific (PTA) & 0 & 0 & 245 & 0 & 0 & 172 & 0 & 0 & 0 & 0 & 0 & 0) \\
\hline MLSO (PTB) & 6 & 2 & 13180 & 0 & 1 & 9915 & 46 & 15 & 0 & 10 & 54 & 50) \\
\hline Other & 1 & 1 & 3172 & 1 & 0 & 3441 & 32 & 32 & 29 & 0 & $(0$ & NK) \\
\hline \multicolumn{13}{|l|}{ Microbiology } \\
\hline Medical & 0 & 0 & 1720 & 0 & 0 & 1407 & 0 & 0 & 0 & 0 & 0 & 0) \\
\hline Scientific (PTA) & 1 & 0 & 1032 & 0 & 0 & 521 & 97 & 0 & 0 & 0 & $(83$ & 0) \\
\hline MLSO (PTB) & 2 & 11 & 13366 & 1 & 0 & 10406 & 15 & 82 & 10 & 0 & ( 20 & 35) \\
\hline \multicolumn{13}{|l|}{ Immunology } \\
\hline Medical & 0 & 0 & 116 & 0 & 0 & 102 & 0 & 0 & 0 & 0 & $(0$ & 0) \\
\hline Scientific (PTA) & 0 & 0 & 189 & 0 & 0 & 145 & 0 & 0 & 0 & 0 & $(0$ & $0)$ \\
\hline MLSO (PTB) & 0 & 0 & 568 & 0 & 0 & 644 & 0 & 0 & 0 & 0 & $(0$ & $0)$ \\
\hline Others & 1 & 0 & 16427 & 0 & 0 & 13262 & 6 & 0 & 0 & 0 & ( 9 & 30) \\
\hline
\end{tabular}

«"V" = Hepatitis A + NANB + "viral hepatitis"

$\mathrm{tP}-\mathrm{Y}=$ person-years of exposure.

(figure) may reflect partly greater awareness and improved working conditions, and partly the use of prophylactic immunisation (before and/or after exposure)..$^{910}$

\section{Tuberculosis (table 2)}

The rate fell from 39 to $18 / 100000$ in the second half of the decade (including one late report). A background of non-occupational infections was scattered throughout the period (14 cases of reactivation or known exposure away from work). Occupational exposure was suspected or known in 15 (including one centrifugation accident ${ }^{11}$ ). No causal factors were reported for the other 12 cases. Post mortem, mortuary, and microbiology technical staff were mainly involved (table 2). Among morbid anatomy, mortuary, and post mortem staff, occupational exposure

Table 2 Tuberculosis 1980-1989

\begin{tabular}{|c|c|c|c|c|}
\hline \multirow[b]{2}{*}{ Group } & \multirow{2}{*}{$\begin{array}{l}\text { Person-years of } \\
\text { exposure } \\
1980-89\end{array}$} & \multicolumn{2}{|c|}{ No of cases reported } & \multirow{2}{*}{$\begin{array}{l}\text { Rate I } \\
100000 P-Y \\
1980-89\end{array}$} \\
\hline & & $1980-84$ & $1985-89$ & \\
\hline \multicolumn{5}{|l|}{ Morbid anatomy } \\
\hline Medical & 5105 & 7 & 0 & 137 \\
\hline Scientific (PTA) & 732 & 0 & 0 & 0 \\
\hline MLSO (PTB) & 12654 & 1 & 0 & 8 \\
\hline Post mortem techician & 2061 & 5 & 5 & 485 \\
\hline Mortuary attendant & 767 & 2 & 0 & 261 \\
\hline \multicolumn{5}{|l|}{ Biochemistry } \\
\hline Medical & 1359 & 0 & 0 & 0 \\
\hline Scientific (PTA) & 4007 & 0 & 0 & $\mathbf{0}$ \\
\hline MLSO (PTB) & 18310 & 2 & 0 & 11 \\
\hline \multicolumn{5}{|l|}{ Haematology } \\
\hline Medical & 3430 & 0 & 0 & 0 \\
\hline Scientific (PTA) & 416 & 0 & 0 & 0 \\
\hline MLSO (PTB) & 23095 & 1 & 1 & 9 \\
\hline Other & 6612 & 1 & 0 & 15 \\
\hline \multicolumn{5}{|l|}{ Microbiology } \\
\hline Medical & 3126 & 1 & 0 & 32 \\
\hline Scientific (PTA) & 1553 & 0 & 0 & 0 \\
\hline MLSO (PTB) & 23772 & 7 & 3 & 42 \\
\hline \multicolumn{5}{|l|}{ Immunology } \\
\hline All & 1897 & 0 & 0 & 0 \\
\hline Others* & 29689 & 3 & 2 & 17 \\
\hline
\end{tabular}

^ Positives = cytology screener; porter; storeman; porter-laboratory assistant; aide. was suspected in six, non-occupational infection (including recurrence of previous infection) in five, while the origin of infection was uncertain in the remainder.

There was a male predominance of 32:9 and a relatively older age distribution for tuberculosis cases, two being over 60 years of age, but this may largely reflect the age range of post mortem and mortuary staff.

\section{Bacillary bowel infections}

These were almost entirely confined to medical laboratory scientific officers working in microbiology (table 3 ), mainly due to shigellae $(n=30)$ and salmonellae $(n=14$, including three typhoid infections). Campylobacter infections (four) also affected other staff and were of suspected food-borne origin in three instances. Not included in table 3 were three uncharacterised outbreaks of diarrhoea, one affecting five staff in a surgical cutup area, ${ }^{12}$ one affecting seven biochemistry staff, ${ }^{12}$ and one caused by Norwalk virus in 12 microbiology workers after a wedding reception. ${ }^{13}$ Most infections followed routine benchwork with stool specimens or isolates, but four were attributed to quality control specimens of shigellae (three $S$ boydii, one $S$ sonnei).

Most cases were not associated with recognised "accidents", which emphasises the risk of benchwork with faecal specimens and with isolates, and highlights the need for scrupulous precautions and uncrowded working conditions for this work.

\section{Sepsis and other infections}

Seven cases of sepsis affected mainly morbid anatomy workers (total 21319 person-years of exposure). They comprised four medical staff, two post mortem technicians, and one office receptionist. Four infections were of confirmed streptococcal origin; the others 
Table 3 Bacillary bowel infections 1980-1989

\begin{tabular}{|c|c|c|c|c|}
\hline \multirow[b]{2}{*}{ Group } & \multirow{2}{*}{$\begin{array}{l}\text { Person-years } \\
\text { exposure } \\
1980-89\end{array}$} & \multicolumn{2}{|c|}{ No of cases reported } & \multirow{2}{*}{$\begin{array}{l}\text { Ratel } \\
100000 P-Y \\
1980-89\end{array}$} \\
\hline & & $1980-84$ & $1985-89$ & \\
\hline \multicolumn{5}{|l|}{ Morbid anatomy } \\
\hline All & 21319 & 0 & 0 & 0 \\
\hline \multicolumn{5}{|l|}{ Biochemistry } \\
\hline \multicolumn{5}{|l|}{ Haematology } \\
\hline Medical & 3430 & 0 & 0 & 0 \\
\hline Scientific (PTA) & 416 & 0 & 0 & 0 \\
\hline MLSO (PTB) & 23095 & 0 & $1^{\star}$ & 4 \\
\hline Other & 6612 & 0 & 0 & 0 \\
\hline \multicolumn{5}{|l|}{ Microbiology } \\
\hline Medical & 3126 & $1^{\star}$ & 0 & 32 \\
\hline Scientific (PTA) & 1553 & 0 & 0 & 0 \\
\hline MLSO (PTB) & 23772 & $20^{\star}$ & 27 & 198 \\
\hline \multicolumn{5}{|l|}{ Immunology } \\
\hline All & 1897 & 0 & 0 & 0 \\
\hline Others & 29689 & 0 & $1^{\star}$ & 3 \\
\hline $\begin{array}{l}\text { *4 Campylobacter } \\
\text { microbiology MLS } \\
\text { Other infections }=\end{array}$ & $\begin{array}{l}\text { one each } \\
\text { rker. } \\
14 \text { flexneri, } 1 \\
\text { a (7 typhimur } \\
\text { a coli } \\
\text { lerae (non-0) }\end{array}$ & $\begin{array}{l}\text { matology } \\
\text { ei, } 4 \text { boydit } \\
\text { typhi, } 2\end{array}$ & $\begin{array}{l}\text { MLSO, } \\
\text { pp", } 1 \text { virc }\end{array}$ & $\begin{array}{l}\text { biology medical } \\
\text { braenderup) }\end{array}$ \\
\hline
\end{tabular}

were one abscess, one paronychia with lymphangitis, and one accidentally acquired staphylococcal ophthalmia. ${ }^{5}$

Brucellosis was reported in two microbiology MLSO(B)s, one in 1982 and the other in 1988 (rate 17 per 100000 person-years in microbiology MLSOs). ${ }^{512}$

Two cases of zoster, one of varicella, two of rubella and one of glandular fever were also reported, which were probably not attributable to occupation.

\section{Discussion}

These studies depend principally on the interest and goodwill of collaborators in different laboratories across Britain. Thus several types of bias may affect the observations. Voluntary participation means that laboratories staffed by persons who are alert to possible occupational risk of infection or who maintain high standards of safety may be more likely to be represented than ones that are not. Likewise, as reporting may relate to events which occurred up to 24 to 30 months before receipt of a study questionnaire, the efficiency and accuracy of recall may vary from laboratory to laboratory, or from reporter to reporter for any one laboratory. Also, the extent to which individual episodes of infection may be investigated for possible occupational risk may vary from laboratory to laboratory, from specialty to specialty, or from time to time. Nevertheless, the series provides an overview of general trends in the prevalence of infections reported by a sample of British clinical laboratories.

Most welcome has been the substantial improvement over the past two decades with the reduction in numbers of occupationally acquired cases of hepatitis, particularly hepatitis B. The advent and use of effective hepatitis $B$ vaccine-and more recently also of hepatitis A vaccine-should reinforce this trend, although safe working practices will continue to be the principal defence against exposure to non-A, non-B (C, D, E, etc) hepatitis and routine hepatitis A virus vaccination seems unnecessary.

Tuberculous infection ought also to be a "residual risk", but the surveys suggest that awareness and vigilance over working conditions remain necessary, especially for post mortem room staff and for microbiology technical staff. Although as yet the concurrence of tuberculous infection and HIV infection has not manifested prominently in Britain, experience elsewhere ${ }^{14}$ warns of potential future risk for laboratory staff anywhere, as the morbidity and mortality of tuberculosis increase and drug resistant strains of Mycobacterium tuberculosis become more prevalent.

Microbiology, as an occupational specialty which requires high standards of safety, featured prominently during the eighties for acquired bacillary bowel infections. Several Shigella sp infections were linked with processing of quality control samples and provide salutary reminders to staff that consistent application of safe procedures underpins good microbiological practice at all times.

Other infections, including sepsis, presented a diverse set of conditions across the spectrum of laboratory specialties. Small numbers were reported for each category of infection and of staff, emphasising the mainly sporadic nature of these individual events. Again, however, the underlying faults which led to many of these problems were almost certainly lapses in good laboratory practice.

In 1978 the "Howie code"15 was published by the Department of Health as an initial statement, in terms of the Health and Safety at Work etc Act 1974, to point British clinical laboratories towards a review of their physical and procedural standing, with the specific aim of raising standards. The code certainly stimulated a response, although some of its recommendations proved contentious. In 1986 the Health and Safety Executive (HSE) published a booklet ${ }^{16}$ intended to assist with implementation of the Reporting of Injuries, Diseases and Dangerous Occurrences Regulations 1985 (RIDDOR). This indicated that the chief purpose of the Regulations was the establishment of a reporting system geared towards accident and prevention of ill health. Specifically included were infections, with leptospirosis, hepatitis, tuberculosis and anthrax named. Also included was "any illness caused by a pathogen referred to in column 2, opposite", the relevant statement being "Work involving a pathogen which presents a hazard to human health". In the accompanying notes of explanation this is enlarged on as work activity "in research or in clinical diagnosis" or "during nursing, ancillary work in a laboratory handling pathogens, and work in human ... postmortem rooms ...". However, it is questionable whether these Regulations have had their intended impact, at least in British clinical laboratories.

Revision and updating of the original Howie code was envisaged and advocated by its authors. Such have been the changes dur- 
ing the decade since "Howie" was published that a new code-or set of codes-for the United Kingdom has been formulated by the Health Services Advisory Committee (HSAC). ${ }^{17-19}$ The new code applies not only to clinical laboratories themselves but also to so-called "side rooms" in a range of clinical settings. Thus the dangers of infection from biological specimens must become more widely known to all who handle such materials. Pertinent comment on various aspects of the new code has appeared recently, ${ }^{20}$ while health and safety principles such as those enunciated by the HSAC form the basis of the new World Health Organization Laboratory Biosafety Manual. ${ }^{21}$ Safety at work must concern all those involved, and surveillance, voluntary or otherwise, of occupationally acquired infections is useful for highlighting shortcomings in techniques, equipment, premises, or personnel.

We are grateful to the Association of Clinical Pathologists for their continued interest and support of these surveys, and for the participation of their members and of colleagues in the Institute of Medical Laboratory Scientists and the British Association in Forensic Medicine. We thank Miss Fiona Johnston for help in producing the present report.

1 Grist NR. Hazards in the clinical pathology laboratory. Proc Roy Soc Med 1973;66:795-6.

2 Grist NR. Hepatitis infection in clinical laboratory staff. Med Lab Sci 1981;38:103-9.

3 Grist NR. Hepatitis and other infections in clinical laboratory staff, 1979. ₹ Clin Pathol 1981;34:655-8.
4 Grist NR. The "ACP Surveys" of Infection. ACP News Winter 1989-90:12-3.

5 Grist NR, Emslie JAN. Infections in British clinical laboratories, 1988-89. F Clin Pathol 1991;44:667-9.

6 Grist NR. Hepatitis in clinical laboratories: a three-year survey. $f$ Clin Pathol 1975;28:255-9.

7 Grist NR. Hepatitis in clinical laboratories 1975-76. f Clin Pathol 1978;31:415-7.

8 Polakoff S. Acute viral hepatitis B reported to the Public Health Laboratory Service. F Infect 1990;20:163-8.

9 Polakoff S. Public Health Laboratory Service surveillance of prophylaxis by specific hepatitis B immunoglobulin in England and Wales during the period 1975-1987. I Infect 1990;21:213-20.

10 Oakley K, Gooch G, Cockcroft A. Review of management of incidents involving exposure to blood in a London teaching hospital, 1989-91. BMf 1992;304:949-51.

11 Grist NR Infections in British clinical laboratories 1980-81. F Clin Pathol 1983;36:121-6.

12 Grist NR, Emslie JAN. Infections in British clinical laboratories 1982-3. f Clin Pathol 1985;38:721-5.

13 Grist NR, Emslie JAN. Infections in British clinical laboratories 1984-5. ₹ Clin Pathol 1987;40:826-9.

14 Di Perri G, Cadeo GP, Castelli F, Cazzadori A, Bassetti S, Rubini F, et al. Transmission of HIV-associated tuberculosis to health-care workers. Lancet 1992;340: 682.

15 Department of Health and Social Security. Code of practice for the prevention of infection in clinical laboratories and post mortem rooms. London:HMSO, 1978.

16 Health and Safety Executive. $A$ guide to the Reporting of Injuries, Diseases and Dangerous Occurrences Regulations Injuries, Diseases and Dangerous Occurrences Regulations 1985. (RIDDOR) Health and

17 Health Services Advisory Committee. Safety in Health Service Laboratories. Safe working and the prevention of infection in clinical laboratories-model rules for staff and visitors. London:HMSO, 1991.

18 Health Services Advisory Committee. Safety in Health Service Laboratories. Safe working and the prevention of infection in clinical laboratories. London:HMSO, 1991.

19 Health Services Advisory Committee. Safety in Health Service Laboratories. Safe working and the prevention of Service Laboratories. Safe working and the prevention of
infection in the mortuary and post-mortem room. infection in the mort

20 Telfer Brunton WA. Safety in the laboratory. $f$ Clin Pathol 1992;45:949-51.

21 World Health Organization. Laboratory Biosafety Manual. 2nd Ed. WHO, Geneva, 1993. 